\title{
Libretos de Criação: experiência de brincar com sons em Rodas Poéticas na educação infantil
}

\section{Creation Libretti: experiencing playing with sounds in Poetic Gatherings in Children Education}

Dulcimarta Lemos Lino* dulcimartalino@gmail.com

Sandra Regina Simonis Richter ${ }^{* *}$ srichter@unisc.br

\footnotetext{
* Professora da Universidade Federal do Rio Grande do Sul (UFRGS), no Departamento de Estudos Especializados da Faculdade de Educação. Doutora em Educação pela Universidade Federal do Rio Grande do Sul (UFRGS).

** Professora do Programa de Pós-Graduação em Educação e do Curso de Pedagogia da Universidade de Santa Cruz do Sul (UNISC), Brasil. Doutora em Educação pela Universidade Federal do Rio Grande do Sul (UFRGS).
} 


\section{Resumo}

O projeto Libretos de Criação: experiência de brincar com sons em Rodas Poéticas na educação infantil" instalou-se no ateliê da universidade com o objetivo de perseguir modos de registrar a experiência lúdica de convivência linguageira. A metodologia das Rodas Poéticas sustentou-se no processo de interação propositiva intensa tomando o corpo como excelência do fazer poético com o movimento da música, da dança e da literatura, na intenção de ampliar repertórios tanto das crianças quanto dos adultos-pesquisadores. Ao afirmar a relevância pedagógica da música em estado de encontro, experimentada no complexo processo de aprender o poder inventivo de habitar a linguagem, o presente estudo tomou como foco reflexivo a experiência de brincar com sons. A investigação em andamento contribui para ampliar a abordagem temática da documentação pedagógica na educação musical, convidando-nos ao exercício diário de narrar e interrogar o currículo.

Palavras-chave: Formação de professores; Educação infantil; Educação musical.

\section{Abstract}

The project "Creation Libretti: the experience of playing with sounds in Poetic Gatherings in Childhood Education" took place in the university's studio with the objective of pursuing ways of recording the playful experience of language. The methodology of the Poetic Gatherings was sustained by a process of intense purposeful interaction, using the body as excellent ability to move poetically to music, dance and literature, aiming at amplifying children's and adults' movement repertoire. While asserting the pedagogical relevance of group musical encounters, realized through the the complex process of learning to inventively express language, this study focuses reflectively on sound-play. This investigation contributes to broadening the themes addressed in musical education research, inviting regular investigation of educational curricula.

Keywords: Teacher education; Children education; Music education. 
A discussão em torno de uma proposta de pesquisa que aqui apresentamos emerge do interesse acadêmico em aprofundar estudos desencadeados no Grupo de Estudos em Educação Infantil na Universidade Federal do Rio Grande do Sul (GEIN/UFRGS) e desenvolvidos na interlocução com as pesquisas do grupo Linguagem, Cultura e Educação (LinCE) no Programa de Pós-Graduação em Educação da Universidade de Santa Cruz do Sul (PPGEdu/UNISC). O ateliê da UNISC tem se constituído no espaço-tempo investigativo de pensar a docência na educação infantil visando desenvolver fundamentação teórico-metodológica no que se refere à formação docente inicial ${ }^{1}$ e continuada ${ }^{2}$ através da dinâmica de Rodas Poéticas ${ }^{3}$. Dinâmica que, ao intencionalmente aproximar música, artes plásticas e literatura, através de ações propositivas entre adultos e crianças no ateliê, vem permitindo constituir uma metodologia sustentada na dimensão poética da linguagem - as Rodas Poéticas - e na relevância pedagógica de planejar, realizar a mediação e documentar a experiência lúdica de convivência linguageira entre adultos e crianças na educação infantil.

A intenção de estudar modos de registrar as interações lúdicas nas Rodas Poéticas através de Libretos de Criação pretendeu problematizar, nas ações educativas com crianças bem pequenas ${ }^{4}$, a separação pedagógica entre modos de agir e habitar a linguagem para resistir à simplificação promovida pela fragmentação nos processos de aprender a interpretar e valorar o mundo. A fragmentação é dada pela histórica polarização no pensamento ocidental entre razão e imaginação, entre teoria e prática, entre sonoro e musical, a qual instala o esquecimento da ludicidade, a eliminação do prazer da atenção estética implicada em toda ação que promove a integração entre sensível e inteligível (RICHTER; BERLE, 2015). Nesse sentido, o desafio deste projeto está em enfrentar a tradição conceitual de conceber a linguagem como representação de um mundo previamente conhecido, fragmentada em "linguagens passíveis de serem isoladas e distinguidas em oral, escrita, visual, gestual, ou seja, em 'verbal' ou 'não verbal'" (BERLE, 2013, p. 107), dada pela desconsideração da experiência temporal do corpo nos processos de aprender a potência poética da criação de sentidos, desde a creche (RICHTER; BOURSCHEID, 2014). Aqui, "o corpo não é primo pobre da língua, mas seu parceiro homogêneo na permanente circulação de sentido" (LE BRETON, 2009, p. 42).

Ao buscar uma escuta fenomenológica à questão da linguagem ${ }^{5}$, concebemos a música como dimensão do corpo linguageiro (LINO, 2015) a partir do sentido que lhe

\footnotetext{
$1 \quad$ Nas disciplinas de Linguagem musical na educação; Linguagem plástico-visual na educação e Literatura infantil e infantojuvenil no curso de Pedagogia da UNISC.

2 Nos cursos de extensão A creche como contexto de vida coletiva (UFRGS, 2011, UNISC, 2012 e 2013) e nos cursos de Especialização em Docência na Educação Infantil (UFRGS, 2014) e Especialização em Educação Infantil (UNISC, 2015).

3 As Rodas Poéticas configuram a constituição de uma "metodologia" que favorece o processo de aprender o poder inventivo de habitar a linguagem como resultado dos projetos de pesquisa Experiência poética e aprendizagem na infância (RICHTER; FRONCKOWIAK, 2010) e Dimensão poética das linguagens e educação da infância (RICHTER; FRONCKOWIAK, LINO, 2011-2013).

$4 \quad$ Aqui, bebês são considerados como crianças de 0 a 18 meses; crianças bem pequenas como crianças entre 19 meses e 3 anos e 11 meses; crianças pequenas como crianças entre 4 anos e 6 anos e 11 meses.

5 A "questão da linguagem" diz respeito à intenção de acolher o mistério da linguagem como fenômeno (MERLEAU-PONTY, 2012) que pode ser interrogado, mas não descortinado. Sempre estaremos diante do mesmo enfrentamento: "[...] a linguagem só permanece enigmática para quem continua a interrogá-la, isto é, a falar dela" (MERLEAU-PONTY, 2012, p. 197).
} 
dá Merleau-Ponty (1999a, p. 206). A dimensionalidade aponta que cada "sentido" é um "mundo" no qual "o mundo" é "este conjunto em que cada 'parte', quando a tomamos por si mesma, abre de repente dimensões ilimitadas - torna-se parte total" (MERLEAU-PONTY, 1999b, p. 202, grifos do autor). Trata-se de pensar que, para crianças bem pequenas, não há sentido em fragmentar possibilidades de ação e interação no mundo em estruturas, conceitos, e/ou representações (BOURSCHEID, 2014). As dimensões do corpo linguageiro emergem para resistir à simplificação de ações educativas alicerçadas em pedagogias adultocêntricas, higienistas e escolarizadoras à medida que sublinham a experiência do corpo e da imaginação criadora como objetivo da educação. O termo linguageiro é aqui utilizado no sentido que lhe dá Paul Ricoeur (1988, p. 41), como o movimento de habitar a experiência humana, o que "significa que nossa pertença a uma tradição ou às tradições passa pela interpretação dos signos, das obras, dos textos ${ }^{6}$, nos quais se inscrevem e se oferecem à nossa decifração as heranças culturais". Assim, compreender a música como dimensão do corpo linguageiro compreende acolher e intencionalmente propor o brincar heurístico com as sonoridades do mundo.

Nessa compreensão, o presente artigo apresenta nossa discussão em torno das notas inscritas de um processo de criação e escuta impressos na experiência de brincar com sons em Rodas Poéticas na educação infantil. Potência reflexiva conquistada na experiência de se constituir professor na especificidade da educação infantil, a partir de um fazer que se aprende no processo singular de fazer-se no coletivo. As Rodas Poéticas configuram a constituição de uma série de atividades que aproximam música, dança e literatura através de ações propositivas entre adultos-pesquisadores e crianças no ateliê da universidade. Os resultados investigativos até o momento vêm apontando que a ação docente na educação infantil exige, tanto dos educadores musicais quanto dos pedagogos, o movimento dinâmico de apropriação dos princípios legais constituídos a partir da organização curricular dos Campos de Experiência7.

Além disso, os retratos sonoros coletados evidenciam que a experiência de brincar com sons emerge enredada nas interações e brincadeiras experimentadas na música, na dança e na literatura, sublinhando a música como esta dimensão do corpo linguageiro que transita e habita o corpo das crianças e dos adultos para ressoar sentidos em uma miríade de significações, sem fragmentações.

Libretos de Criação é a denominação que conferimos aos registros produzidos pelos acadêmicos para carregar a memória do corpo linguageiro convidado a experimentar o mundo nas Rodas Poéticas. Em sua origem, a palavra libreto se refere ao texto a partir do qual são compostos oratórios, óperas, ou cantatas, ao passo que criação, nos remete a invento, elaboração, formação. No presente estudo, os libretos de criação pretendem sublinhar a potência de um registro que procura "deixar marcas, tecer memórias, fazer história" (OSTETTO, 2008, p. 8). Tal documentação parte de um texto de proposições que tem como intencionalidade educativa abordar, na educação infantil,

\footnotetext{
6 Para Ricoeur (1988), o termo "texto" compreende todo tipo de texto, descritivo ou poético, pois o que há a interpretar, em um texto, é uma proposição de mundo, o projeto de um mundo que poderia habitar e onde poderia projetar "meus" possíveis.

7 Propósito constituído a partir da contínua reflexão articulada no campo investigativo pela classe docente e disposta nas DCNEI (BRASIL,
} 2009) e na BNCC (BRASIL, 2017). 
a interação entre adultos e crianças pequenas nas Rodas Poéticas a partir da alteridade linguageira que marca a descontinuidade temporal entre saberes e fazeres de ambos. $O$ estudo da organização curricular e da bibliografia investigativa pretende criar um modo de registrar como prática reflexiva aberta ao diálogo e à multiplicidade de experiências envolvidas na ação de brincar com sons.

Nessa multiplicidade, os libretos de criação emergem como registro das narrativas dos adultos-pesquisadores das ações vivenciadas nas Rodas Poéticas a partir do encontro com as crianças. Podem incluir relatos orais, atividades, descrições, mini-histórias, fotos, vídeos, gravações, músicas. Os adultos-pesquisadores assumem a responsabilidade de, com as crianças, registrar e dar forma à experiência de documentar as ações vividas no ateliê da universidade. Assim, os libretos de criação acabam funcionando como uma partitura, uma notação na forma impressa que inventaria a experiência de participar das Rodas Poéticas. Nosso objetivo é refletir sobre as marcas da memória desse registro, sustentando argumentos em favor das interações lúdicas que podem emergir dos encontros linguageiros entre crianças e adultos como modos de produção e apropriação sonora e musical na educação infantil.

\section{Educação infantil e educação musical}

A educação infantil, como primeira etapa da educação básica, compreende o início e o fundamento do processo educativo das crianças brasileiras. Para tanto, segundo as Diretrizes Curriculares Nacionais para a Educação Infantil - DCNEI (BRASIL, 2009), essa etapa tem como função articular em suas propostas pedagógicas o universo de experiências, conhecimentos e habilidades das crianças, a partir do acolhimento dos conhecimentos e vivências constituídos no seu ambiente familiar e no contexto de sua comunidade. Assim, a criança é concebida como

[...] sujeito histórico e de direitos, que interage, brinca, imagina, fantasia, deseja, aprende, observa, experimenta, narra, questiona e constrói sentidos sobre a natureza e a sociedade, produzindo cultura. [...] seres que, em suas ações e interações com os outros e com o mundo físico, constroem e se apropriam de conhecimentos. (BRASIL, 2009, p. 29).

As DCNEI (BRASIL, 2009, p. 33) afirmam como eixos estruturantes, nas práticas pedagógicas, "as interações e as brincadeiras" como experiências através das quais as crianças podem se apropriar de suas experiências a partir de suas ações e interações no e com o mundo. Nessa compreensão, a Base Nacional Comum Curricular para a Educação Infantil (BRASIL, 2017) assegura seis direitos de aprendizagem - conviver, brincar, participar, explorar, expressar-se e conhecer-se - a partir de uma organização curricular estruturada em Campos de Experiência como modo de conceber esses processos em sua vinculação com a experiência vivida das crianças. Esses direitos atravessam as propostas pedagógicas direcionadas às crianças, apontando seu papel ativo "em ambientes que as convidem a vivenciar desafios e a sentirem-se provocadas a resolvê-los, 
nas quais possam construir significados sobre si, os outros e o mundo social e natural" (BRASIL, 2017, p. 33).

Nessa organização curricular, a partir das contribuições italianas de Borgui e Guerra (1999), não se define uma disciplina ou área específica de conhecimento, um conteúdo a cumprir, nem atividades a desenvolver. Os Campos de Experiência constituem "um arranjo curricular que acolhe as situações e as experiências concretas da vida cotidiana das crianças e seus saberes, entrelaçando-os aos conhecimentos que fazem parte do patrimônio cultural" (BRASIL, 2017, p.36) Sendo assim, "possibilitam aos professores constituírem uma compreensão mais atualizada e complexa das áreas de conhecimento e das disciplinas acadêmicas, pois favorecem a visibilidade de interações entre elas" (BARBOSA; RICHTER, 2015, p. 192).

Logo, a organização curricular na educação infantil não se fundamenta essencialmente na preparação das crianças à escolarização do ponto de vista do conhecimento disciplinar, mas propicia e associa experiências na instituição escolar para ampliar seu conhecimento do mundo físico e sociocultural através de cinco Campos de Experiência distintos: 1) O eu, o outro e o nós; 2) corpo, gestos e movimentos; 3) traços, sons, cores e formas; 4) oralidade e escrita; 5) espaços, tempos, quantidades, relações e transformações (BRASIL, 2017, p. 36-38).

Ao considerarmos a infância como construção social (SARMENTO, 2003) e compreendermos com Heywood (2004) que o papel da criança e da infância variam de acordo com as formas de organização da sociedade, entendemos que os Campos de Experiência, propostos na Base Nacional Comum Curricular (BRASIL, 2017), podem movimentar a música em sua potência lúdica e poética de constituir sentidos em uma miríade de formas de expressão. Nesse sentido, a intencionalidade docente tem o compromisso fundamental de organizar propostas pedagógicas, no contexto coletivo da vida cotidiana das crianças, que promovam um tempo para "compartilhar a vida; brincar e jogar; e acolher suas narrativas" (BARBOSA; FOCHI, 2015, p. 65).

Se as propostas pedagógicas dispostas à educação musical de crianças pequenas frequentemente emergem relacionadas às fases do desenvolvimento cognitivo e a consequente observação docente à aquisição de hábitos e habilidades estruturados em ordem linear e crescente (SERAFINE, 1988; DAVIDSON; SCRIPP, 1991; SLOBODA, 1988; SLOBODA; DELIEGE, 1996; BEYER, 1994; GORDON, 2000), a experiência de lançar-se ao registro e à documentação de libretos de criação propõe aos adultos-pesquisadores se situarem como participantes reflexivos da ação docente. Planejar, organizar e realizar encontros com música nas Rodas Poéticas podem promover a possibilidade de acompanhar percursos para tematizar autoria de crianças e adultos, na perspectiva de ampliar "metodologias e pressupostos teóricos distintos" (ILARI; BROOCK, 2013), tematizando seus processos investigativos (ILARI; YOUNG, 2016).

O que aqui renunciamos é à concepção de educação musical fortemente dominada pela psicologia e ao seu modelo de desenvolvimento de uma criança universal, bem como a aplicação de um método de musicalização determinado e a perdurável fixação pedagógica no que a criança deve aprender (agudo, grave, forte, piano, pulsação, compasso, leitura da partitura), para inaugurar narrativas pedagógicas que documentem e 
registrem o movimento de saberes e fazeres que sublinhem a autonomia e a alteridade linguageira da criança em relação ao adulto. Dessa forma, os conteúdos do trabalho educativo musical não seguem um cronograma prescrito antecipadamente, mas emergem a partir da experiência compartilhada na ação de brincar com sons nas Rodas Poéticas, isto é, da música posta em estado de encontro intersubjetivo entre as crianças e os adultos na ação de barulhar (LINO, 2008).

\section{Libretos de Criação e Documentação Pedagógica}

Madalena Freire (1983; 1996), no cenário educacional brasileiro, inaugura a abordagem temática do registro e da documentação pedagógica na educação infantil convidando-nos ao exercício encantado de viver a "Paixão de Conhecer o Mundo" (FREI$\mathrm{RE}$, 1983). Bastante influenciada pelos documentos produzidos pela pedagoga, Cecilia Wauschauer (1993), Freire reflete sobre a roda e seu registro, promovendo importante abertura ao diálogo histórico-reflexivo em torno da educação da infância. De modo tão inaugural quanto complementar, Ostetto $(2000,2006,2008)$ registra o cotidiano da educação infantil e a formação docente no curso de Graduação em Pedagogia para sublinhar a autoria das educadoras e a constante circularidade entre teoria e prática na formação pedagógica, tendo como campo privilegiado os acadêmicos oriundos da disciplina de Estágio-Docente.

As obras acima mencionadas estabelecem proximidade com a abordagem da documentação pedagógica concebida por Malaguzzi (2001). Obstinado pela ideia de registrar os percursos das crianças, o estudioso incentivava seus professores a terem um caderno de bolso para escrever: falas das crianças, observações do cotidiano, hipóteses que elas lançavam sobre os temas em estudo, enfim, tudo que pudesse compor a construção e a atualização dos projetos educativos. Malaguzzi (2001) buscava que os professores incorporassem em sua prática o hábito da escrita e que, a partir dela, refletissem sobre o trabalho pedagógico. Ao dedicar-se à Pedagogia da Escuta, Malaguzzi indica a relevância da ação educativa baseada na escuta das crianças: "Se não aprendermos a escutar as crianças, será difícil aprender a arte de estar e conversar com elas" (HOYUELOS, 2004, p. 131).

Tomaselli e Zocchi (2009) entendem que a documentação pedagógica configura instrumento fundamental para dar testemunho, compreender o sentido e acolher o significado que emerge da experiência educativa. Para os estudiosos, a reflexão investigativa surge na "tentativa de enxergar e entender o que está acontecendo no trabalho pedagógico e o que a criança é capaz de fazer sem qualquer estrutura predeterminada de expectativas e normas" (DAHLBERG; MOSS; PENCE, 2003, p.132). Ao criarem memórias, os adultos-pesquisadores podem rever a experiência e os eventos anteriores, favorecendo a emergência de novas leituras, interpretações e reconstruções do passado. Isso implica dizer que a documentação é "um processo dialético, baseado em laços afetivos e também poéticos; não apenas acompanha o processo de construção do conhecimento como, em certo sentido, o fecunda" (RINALDI, 2012, p. 134). 
Documentar é ao mesmo tempo processo e conteúdo, "uma dimensão processual que gera o conteúdo e também se utiliza do conteúdo para sua própria continuidade" (FOCHI, 2013, p. 79) Aqui, a ação pedagógica de planejar Rodas Poéticas incorpora o pensamento de Malaguzzi (2001), porque acompanha percursos que não são possíveis de serem previstos e nascem da emergência da experiência. Isso porque "precisamos seguir as crianças e não os planos. São as crianças em suas brincadeiras e investigações que apontam os caminhos, as questões, os temas e os conhecimentos de distintas ordens que podem ser por elas compreendidos e compartilhados no coletivo" (BARBOSA; RICHTER, 2015, p. 195).

No campo específico da educação musical, a temática da documentação pedagógica começa a ser registrada e debatida na direção de se tornar material para rever o vivido, atribuindo-lhe outros significados e projetando outros fazeres desejados ou necessários para marcar autoria, protagonismo e criação das crianças e dos adultos (SOTO; VIOLANTE, 2016; PEREIRA, 2013; AKOSCHKY et al., 2009; CABANELLAS; HOYUELOS, 1998; BERTOLA et al., 2011; SILVA, 2014). Nessa trajetória, observa-se que a escuta da experiência de brincar com sons emerge integrada às experiências lúdicas cotidianas que compartilham emoções, realizam ações conjuntas, oferecem disponibilidade corporal, organizam cenários, estendem o tempo para sustentar a liberdade, a ludicidade, a música e a festa na dimensionalidade do corpo linguageiro.

No contexto brasileiro, os pioneiros trabalhos dos educadores musicais Marisa Fonterrada (2004; 2008; 2015), Teca Alencar de Brito (2001; 2003; 2009) e Carlos Kater (2001; 2013; 2016) têm nos ajudado a compreender os saberes e fazeres das crianças e da docência como um processo coletivo contínuo de formação, sistematização e principalmente disposição às práticas criativas. Ao registrar, compartilhar e comentar experiências musicais lúdicas, esses educadores destacam a prática reflexiva escrita, gravada (CDs), filmada (DVDs) ou verbalizada (palestras/oficinas), reforçando o prazer da ação docente e da aprendizagem em grupo. Além disso, a articulação e a complementariedade sugeridas por Bellochio (2017) nas ações formativas, investigativas e nas discussões de práticas do professor de referência (unidocente) e do educador musical contribuem para "potencializar as formas de organização de conhecer das crianças" (BELLOCUIO, 2017, p. 45). Segundo Bellochio (2017), a contínua investigação empreendida há 20 anos no grupo de pesquisa Fapem/UFSM (Formação, Ação e Pesquisa em Educação Musical da Universidade Federal de Santa Maria) tem demarcado o urgente e necessário trabalho conjunto entre professores de música e pedagogos para a ampliação e para o aperfeiçoamento da experiência educativa musical.

Neste contexto, os distintos relatos de experiência propostos e constituídos pela ABEM (Associação Brasileira de Educação Musical), pela ANPPOM (Associação Nacional de Pesquisa e Pós-Graduação em Música) e pela FLADEM (Federação Latino-Americana de Educação Musical), bem como a oportuna edição contínua da revista Música na Educação Básica (ABEM, 2009), com sugestões de propostas pedagógicas reflexivas, podem contribuir efetivamente para indicar a relevância de promover aprofundamento e alargamento na temática da documentação pedagógica no contexto brasileiro da educação musical, especialmente no campo da educação infantil. 
A documentação das Rodas Poéticas em Libretos de Criação emerge, pois, no presente estudo para sublinhar que "ao registrar, o educador afirma-se autor" (OSTETTO, 2015, p. 32). Para tanto, os adultos-pesquisadores poderão constituir narrativas à escuta dos percursos que nascem na emergência da experiência. Sem um marco teórico explícito a priori, propomos-nos a encontrar uma estratégia que nos permita estudar determinada ação sem simplificá-la. Logo, não temos

[...] um marco teórico explícito descritivo de um sistema musical, poético, ou plástico, que preexista antes da ação infantil, mas focalizamos a observação no fluir das ações no tempo e no espaço, como um alento que marca, com suas próprias pautas, o decorrer natural de todo o processo de vida. (CABANELLAS; ESLAVA; ESLAVA; POLÔNIO, 2007, p. 94).

A docência é esse processo de vida que na presente investigação se propõe a capturar nos Libretos de Criação os processos de escuta e criação envolvidos na constituição de formar-se educador da infância ao viver Rodas Poéticas. Libreto carregado de memórias que não necessitam ser traduzidas nem transferidas, pois o corpo é a ferramenta e a conclusão, o princípio e o fim, a partitura escrevendo-se e soando. O corpo é aquilo que cria, desvela, executa e se mostra, é o mote da experimentação que movimenta sentidos. Cabe ainda destacar que a forma de coleta e registro da experiência investigativa está sendo construída pelos adultos-pesquisadores a partir do convívio no grupo, das leituras realizadas e das atividades intencionalmente planejadas e experimentadas nas Rodas Poéticas e no Grupo de Pesquisa Música e Infância (FACED/UFRGS).

\section{Rodas Poéticas}

As Rodas Poéticas habitaram o espaço físico do ateliê da universidade como lugar temporalizado da experiência de planejar, organizar e realizar encontros com música, com dança e com literatura. Tinham como objetivo contribuir com o processo educacional de apresentar materialidades que as crianças têm muito interesse em manusear e curiosidade de transformar. A intenção era promover encontros "brincantes" entre adultos e crianças, e não "ensinar" música, dança ou literatura, como modos de ambos ampliarem repertórios em suas interações com os outros e as coisas do mundo. $\mathrm{O}$ importante era desafiar as crianças a ensaiar, a investigar, a explorar e a transformar sentidos em narrativas. Afinal, o ateliê

[...] nunca pretendeu ser um tipo de espaço recluso e privilegiado, como se lá apenas fosse possível produzir a linguagem da arte expressiva. [...] em vez disso, um local onde as diferentes linguagens das crianças podiam ser exploradas por elas e estudadas por nós. [...] espaço rico em materialidades, ferramentas e pessoas com competências profissionais. (EDWARDS; GANDINI; FORMAN, 1999, p. $66)$. 
Um lugar e um tempo de parceria que investe no trabalho cooperativo no qual crianças e adultos-investigadores dispõem de tempo para gradualmente conquistarem repertórios de mundo: sonoridades, músicas, silêncios, paisagens sonoras, enfim, gestos de sentido para sublinhar convivência e intimidade no mundo. Para Hoyuelos (2007), o ateliê funciona como pedagogia da expressão, “lugar de provar, explorar, equivocar-se, fazer loucuras, inventar, indagar, sair da rotina. Convida a atrever-se a romper com o cotidiano. Supõe uma perturbação para sair dos estereótipos, das fórmulas fechadas". Assim, o ateliê é o lugar e o tempo do acontecimento lúdico-sonoro, da interrogação, do refinamento, do encanto, da escuta, das destemporalidades, no qual também podemos complexificar e refinar modos de escuta, observação e registro.

O ateliê, em qualquer lugar ${ }^{8}$, constitui um espaço e um tempo da música em estado de encontro. Aqui o simples convite à imersão na "Caixa de Silêncio9" pode convidar o ouvido a perceber a paisagem sonora constituinte da vida cotidiana. Nessa convivência linguageira, crianças e adultos-pesquisadores respeitam seu direito à organização e à estruturação como um espaço/tempo de exploração e pesquisa. Assim, se o ensino fundamental tem como objeto o ensino, "um espaço privilegiado para o domínio dos conhecimentos básicos" (ROCHA, 2001, p. 31), poderá ter uma sala de aula com quadro-negro, classes e cadeiras dispostas. Porém, se a educação infantil tem como espaço privilegiado as relações (MALAGUZZI, 1999), as interações e as brincadeiras (BRASIL, 2009), o ateliê se apresenta como o espaço/tempo "propositivo, [onde] podemos criar ações pedagógicas significativas e enriquecedoras para as crianças" (KAERCHER, 2015, p. 109).

As Rodas Poéticas ocorrem no espaço físico do ateliê como "unidades de vida" (APPELL; DAVID, 2010, p. 31) ou nossa "sala de referência" (BONDIOLI, 2004). Um espaço disponível para adultos e crianças movimentarem a experiência de brincar com sons no complexo arquitetônico interno e externo do ateliê. Isso porque a Faculdade de Educação da Universidade Federal do Rio Grande do Sul (FACED/UFRGS) está situada em espaço privilegiado, próximo a diferentes e provocantes entornos sonoros. Para Bondioli (2004, p. 23), “o ambiente referência de um grupo qualifica a sua pertinência e, como tal, é vivenciado como espaço próprio que deve ser defendido de estranhos ou que deve ser aberto a eventuais hóspedes".

Os procedimentos tomados na metodologia das Rodas Poéticas (RICHTER; FRONCKOWIAK, 2010) envolvem um processo de interação propositiva intensa com as crianças pequenas e os adultos-pesquisadores, porque ressoam as ações planejadas e organizadas pelo grupo em torno dos espaços e tempos para experimentar o som, o silêncio, as músicas, as paisagens, objetos sonoros, entre outros. Isso porque "as crianças não explicam, não se apresentam, elas brincam, elas jogam. Elas tomam decisões, enfrentam os acasos, ensaiam tentativas, repetem, rearranjam, enfim, buscam experimentar a tensão que é interrogar o mundo sem cindir imaginação e razão"

\footnotetext{
8 Não há necessidade de "construir" um "ateliê', mas habitar um lugar na intencionalidade de promover experiências lúdicas com materialidades e ferramentas.

9 Caixa de Silêncio: um cubo preto de dois metros de profundidade, construído artesanalmente pelos pesquisadores para que as crianças experimentassem a escuta da paisagem sonora exterior.
} 
(RICHTER; FRONCKOWIAK, 2011, p. 39).

A investigação envolve seis adultos-pesquisadores e 12 crianças na faixa etária variante entre dois e três anos de idade, oriundas da mesma turma na Escola Municipal de Educação Infantil da cidade de Porto Alegre. Todo o quadro de adultos-pesquisadores nessa investigação é formado por professores com experiência em instituições escolares formais e informais assim dispostos: a) dois estudantes do curso de Graduação em Pedagogia; b) dois educadores musicais (um Bacharel em Violão e um percussionista autodidata); c) dois professores da rede municipal especialistas em educação infantil, um deles formado em dança. As Rodas Poéticas ocorrem no espaço do ateliê da universidade uma vez por mês, contemplando o primeiro e o segundo semestres letivos de 2017. A tarefa dos adultos-pesquisadores consiste em planejar, organizar e realizar Rodas Poéticas com as crianças e participar dos eventos promovidos pelo Grupo de Pesquisa Música e Infância (GEIN/UFRGS), mantendo assiduidade nos encontros promovidos pelo coordenador e cumprindo o cronograma elaborado. Os adultos-pesquisadores se envolvem cooperativamente nas reflexões tomadas, além de organizarem seus registros na forma de libretos de criação.

Cabe destacar que a brincadeira em cada Roda Poética é provocada pela especificidade da materialidade oferecida, pelo "como" fazer, e não pelo "o que" as crianças devem fazer. Ou seja, a brincadeira surge no desafio imposto pela resistência e os limites envolvidos na materialidade experimentada. Por essa razão, nos encontros com os adultos-pesquisadores, dedicamos bastante tempo a pensar sobre a temática das materialidades sonoras e musicais. É importante também ressaltar que as atividades propostas nas Rodas Poéticas têm alcançado uma didática participativa "com procedimentos e processos que poderiam ser comunicados e compartilhados" (RINALDI, 2012, p. 132), porque movimentavam um corpo de sentidos improvisados. Aqui adultos-pesquisadores e crianças experimentam as práticas criativas como ato poético, fabricador de mundos.

\section{Experiência de brincar com sons}

Investigar a experiência de brincar com sons em Rodas Poéticas na educação infantil requer tempo e insistência para reconhecer que as crianças e os adultos-pesquisadores apreciam a música como dimensão do corpo linguageiro (LINO, 2015). Para tanto, entregam-se à potência lúdica instalada no mundo, movimentando também o som, os ruídos, os silêncios, as manchas, o volume, o grito, a vibração, as músicas. Nessa experiência, as interações ocorreram atravessadas pelo que não podia ser antecipado: o viver. A diferença então se instala no "tom" das interações, nos ritmos de cada um, na constituição dos pares, na empatia e simpatia em fazer mais uma vez (RICHTER; FRONKOWIAK; LINO, 2013). Compreendemos que cada corpo é único e diferente, por isso, a experiência de habitar a linguagem é imediata e infinita, mas nasce na realidade, no contexto da vida coletiva institucional onde os docentes dispõem intencionalmente tempos e espaços para a experiência de brincar com sons.

O encontro de adultos-pesquisadores e crianças nas Rodas Poéticas tem resgatado a memória lúdica e poética dos professores na experiência de barulhar (LINO, 2008), isto 
é, na ação de brincar com sons. Nessa atividade, a música em estado de encontro toma a ação dos professores, porque testemunha a aventura autônoma de brincar, que vibra incertezas, escapa do domínio individual e mina expectativas prévias. Como que flutuando no mar da expressividade, os adultos aceitam a interrogação para tocar o que deles escapa. Nesse instante, enfrentam o risco de botar o som no corpo, na temporalidade e na espacialidade do mundo, na densificação das impressões, sensações e sincronicidades heterofônicas do discurso musical. Intuitivamente, os professores exploram o potencial expressivo do corpo e das materialidades expostas, aceitando o limite de correr risco. Assim, a mão em movimento toca a ressonância do corpo elástico, a pregnância de coerências musicais instituídas, a criação (LINO, 2008, p. 131). Nesse contexto, o tempo apresenta-se como a força do ser que toma decisões na vida prática, inventando uma expressividade híbrida, onde a música incorpora outras linguagens simultaneamente, sem fragmentações. Aqui o ato de interrogar une sensível e inteligível, sonoro e musical, teoria e prática. Logo entendemos que nós não tocamos o mundo porque temos mãos. Mas tocamos o mundo porque sabemos tocar.

Pesquisas anteriores (RICHTER; FRONKOWIAK; LINO, 2013) indicaram que, na experiência de planejar, organizar e realizar Rodas Poéticas, o grupo de adultos-pesquisadores tem ensaiado abandonar a condição de espectador do currículo escolar para se constituir em interrogador do mesmo. O espectador é aquele que perdeu a capacidade de vivenciar a experiência. Esse estudo entendeu que o acesso dos adultos-pesquisadores ao ateliê prioriza a função docente como envolvimento colaborativo e a narratividade como processo de interlocução para inventar um currículo pautado nas narrativas que esses adultos e as crianças podem estabelecer no cotidiano, a partir do vínculo das experiências compartilhadas com a vida. Nelas os adultos-pesquisadores ensinam o corpo intuitivamente a tocar a si mesmo, ao outro e ao mundo, afirmando a relevância pedagógica de aprender o poder inventivo de habitar a linguagem.

Portanto, a experiência de brincar com sons parece invadir os diferentes Campos de Experiência propostos na organização curricular da educação infantil (BRASIL, 2017) para sublinhar a música como dimensão do corpo linguageiro. Corpo que toca para ressoar sentidos, por desejo, pertencimento, ludicidade, escuta ou pura alegria. Ao compor o seu percurso curricular na simultaneidade que constitui a sua história de vida, adultos-pesquisadores e crianças provam as resistências e as consistências do mundo, investigam relações e transformações, gestos e movimentos, provam tempos e espaços, escutando limites e possibilidades.

\section{Impressões}

$\mathrm{Na}$ experiência de brincar com sons em Rodas Poéticas, as crianças e os adultos-pesquisadores têm nos mostrado que a música emerge como instalação do mundo, no qual o tempo e o espaço da expressão não se constituem como a tradução de um pensamento claro, pois estes são os que já foram ditos em nós, ou pelos outros. Assim, a concepção não pode preceder a execução (MERLEAU-PONTY, 1991). Na ação de explorar sonoridades, silêncios e músicas, o acaso, o encontro e a convivência têm se constituído 
como molas da ação poética infantil. Memória de um corpo passado, presente e um devir que nem mesmo se tem consciência naquele momento. Então compreendemos que a experiência de brincar com sons carrega a necessidade humana de sentir antes de dar sentido.

Os diferentes libretos de criação apresentados têm nos convidado a interrogar as fronteiras entre o sonoro e o musical. As crianças estão na ressonância sonora com a mesma poética e ludicidade que nas canções brasileiras que embalam as atividades no ateliê. Para o grupo investigado, o ruído parece emergir como elemento de renovação do discurso sonoro porque convida o ouvido a entoar memórias incorporadas e, sistematicamente, inventar outras formas de soar, comunicar, conversar. Segundo Atal (1977, p. 9), "com o ruído nasce a desordem e seu oposto: o mundo". As crianças parecem querer conhecer o mundo (todas as músicas da música), mas também transformá-lo (imaginando outras formas de pôr-se no som) (LINO, 2014).

Consideramos que é o apelo à ordem que faz da música esta organização concebida pelos compositores de sons e silêncios. Por isso, a música como tal é conservadora. Guarda uma memória. Congela um tempo. Ressoa uma trajetória. Define uma fôrma. Apresenta um ponto de escuta. Expressa a escolha de um corpo que foi convidado a tomar decisões de ação na vida cotidiana. Um corpo capaz de experimentar e colocar-se diante do indeterminado, do imprevisível, do inexistente. Do som, como ruído, mescla ou tom, e do silêncio, como tensão ou repouso; para então tatuar o seu jeito de ser, inventando a sua música (LINO, 2014).

A partir de nossas investigações em torno da dimensão poética da linguagem, podemos afirmar que o planejamento coletivo das Rodas Poéticas, realizado pelo grupo de adultos-pesquisadores no tempo e espaço do ateliê, permite deslocar a concepção de didática como mero processo de ensino de conteúdos estanques, tendência adultocêntrica muito presente na cultura escolar. Essa presença nos força a interrogar a cômoda posição positivista que isola e lineariza os componentes da escola - currículo, conteúdos, avaliação, planejamento, rotina de atividades (SOARES, 1985) para enfrentar o desafio da coexistência de um projeto educativo com as crianças. O desafio está em enfrentar a dualidade e a incoerência entre teoria e prática, cuidado e educação, público e privado, sonoro e musical, entre o vivido e as áreas específicas de conhecimento, como modo de sublinhar que o processo de escolarização da potência inventiva da linguagem necessita ser interrogado. Dessa forma, as crianças não parecem interessadas em aprender curto ou longo, agudo ou grave, forte ou piano, mas têm o desejo de experimentar os contrastes das materialidades sonoras em seus excessos, ou seja, compartiIhar seus contrastes e nuanças, mexer na paisagem sonora, vibrar com os acalantos, os toques no sopapo e a música tradicional da cultura da infância.

Mesmo que nosso foco investigativo se concentre na experiência de brincar com sons, temos evidenciado nas atividades propostas no ateliê com dança e literatura quanto o ruído e o silêncio edificam e enredam produções, interpretações e improvisações dos adultos-pesquisadores e das crianças. Na dança, o gesto parece desenhar o som, e a escuta atenta alicerça as decisões das crianças. Entregam-se a coreografar diferentes melodias, encantando-se com os movimentos de abertura e fechamento das mãos, dos 
braços e das pernas em distintas direções, esforçando-se para realizar a execução de forma alternada e simultânea. Tal atividade é quase que prioritariamente conduzida pela entonação da voz, que orienta o corpo a permanecer por mais um momento estendido ou relaxado.

Ao caminhar na areia, as crianças descobrem que podem deixar marcas, e isso as excita. Então vocalizam diferentes timbres e tonalidades improvisadas para sinalizar o caminho e a intensidade de seus passos. Imitam os passos reproduzindo as vozes de animais das fábulas escutadas no ateliê. Assim, marcam passos de formigas, lagartixas, leões e ursos e logo estão procurando um jeito de fazê-los soar; divertindo-se com o rastro que seus pés deixam atrás de si. As crianças e os adultos adoram inventar células melódico-rítmicas para recordar personagens literários que lhes são caros. Batem palmas, pulam, imitam sons onomatopeicos, estalam a língua para interpretar e demonstrar sua presença. Logo descobrem que as sonoridades que saem de sua boca dependem de como o ar passa por ela. Além disso, compreendem que, no coletivo, podem soar com maior intensidade, provocando o excesso dessa expressividade e provando as coleções com seus pares. Nesta incursão, as crianças parecem preferir escutar a música que acabam de inventar, entoar o hino de seu clube esportivo preferido, emparelhar palavras que rimem, contar quantas teclas tem o piano, ver o que tem dentro do buraco do violão. Querem compartilhar vivências sociais e pessoais da vida comum, das práticas sociais, das culturas populares, das relações e das interações que experimentam.

Ao professor cabe possibilitar encontros, favorecer interações lúdicas, propor relacionamentos, vincular comunicações, constituir tempos e espaços. Sem pretender ensinar a criança a tocar um instrumento, esse encontro encoraja adultos-pesquisadores e crianças a iniciarem um percurso na educação musical, experimentando outros modos de sentir, perceber e agir no mundo. A metodologia proposta pelas Rodas Poéticas tem perseguido as interrogações através da interlocução das crianças e dos adultos-pesquisadores no ateliê, experiências provocativas na música, na dança e na literatura, porque priorizaram o envolvimento colaborativo e a narratividade como processo de documentação, a partir do vínculo da música com a vida.

Nas Rodas Poéticas as crianças e os adultos estão vivendo a experiência de entrar em linguagem brincando. No ateliê - espaço acolhedor e sem o tempo medido do metrônomo - as crianças podem desfrutar um tempo sem tempo, isto é, um tempo de descontinuidades. Quando tentamos entender como Pedro aprendeu a tocar a clave da Roda de Coco, ele prontamente responde: "eu que me ensinei!" (Diário de Campo, 2017, p. 32). Repetidas vezes escutamos essa fala no cotidiano escolar quando manifestamos curiosidade em saber o processo que ocorre quando as crianças inventam suas brincadeiras. Tal potência poética de produção de sentidos emerge das dimensões linguageiras do viver - presentes no corpo em tempo e espaço vivido - provocador de sentidos e aprendizagem (LINO, 2015).

Desta forma, a experiência temporal diz respeito ao devir narrativo e, por isso, habitamos as dimensões da linguagem de muitos modos. $O$ ateliê constitui um espaço acolhedor dos diferentes tempos das crianças e dos adultos-pesquisadores em oposição à "sala de aula" na qual tudo deve ser igual para todos, e os ritmos das crianças 
e dos adultos condicionados a uma unidade, a de aluno ou a de professor. As crianças habitam o ateliê e habitar é significar, "potência aberta e indefinida, ao mesmo tempo de apreender e de comunicar um sentido, pela qual nos transcendemos em direção a modos de agir, em direção ao outro, em direção ao próprio pensamento, pelo nosso corpo e nossa fala" (RICHTER; BERLE, 2015, p. 135).

Para Agamben (2011), há infância porque o humano não fala desde sempre, por isso as crianças têm a potência de entrar em linguagem. O filósofo destaca que o gato nasce e morre miando, porém, ao contrário, o humano não pode entrar na língua como um sistema de signos sem transformá-la radicalmente, sem constituí-la como discurso (AGAMBEN, 2011, p. 77). Para Agamben, a infância aparece como a dimensão histórico-transcendental do humano e a linguagem como o lugar da experiência. Uma experiência de habitar a linguagem consiste numa ação que nos toca, que nos acontece, que nos expõe. Larrosa (2002, p. 21) nos ensina que uma experiência se prova (do latim experiri), requer interrupção, cultiva a escuta, mobiliza o corpo.

As Rodas Poéticas têm se estabelecido como um lugar e um tempo de parceria que investe no trabalho cooperativo no qual crianças e adultos-investigadores dispõem de tempo para gradualmente conquistarem repertórios de mundo: sonoridades, rimas, músicas, entonações, gorjeios, gestos, coreografias, para então explorarem, em suas escolhas, possibilidades de significar a coexistência no mundo. Para Hoyuelos (2007, p. 98), o ateliê funciona como pedagogia da expressão, "lugar de provar, explorar, equivocar-se, fazer loucuras, inventar, indagar, sair da rotina. Convida a atrever-se a romper com o cotidiano. Supõe uma perturbação para sair dos estereótipos, das fórmulas fechadas". O ateliê se constituiu no lugar e no tempo do acontecimento lúdico da pesquisa, do refinamento, do encanto, da escuta, das destemporalidades, no qual os adultos também podem complexificar e refinar modos de escuta, observação e registro. Além disso, o ateliê emerge como espaço de "ter ideias" para o cotidiano da sala de aula (Professora A - Diário de Campo, 2017, p. 11).

Esse projeto de pesquisa também tem se apresentado como uma possibilidade de aproximação para interrogar as fragilidades e potencialidades de constituir-se professor na educação infantil, contemplando a música como uma dimensão do corpo linguageiro. Experimentar o fazer sonoro e musical na educação infantil movimenta a docência porque nos faz entender que, como as crianças, "somos musicais [...] e não precisamos necessariamente ser músicos! [...] Fazer música com crianças pode fazer barulho; atrapalhar a outra turma; nos colocar na posição de desafinado e sem ritmo [...]" (Professora B - Diário de Campo, 2017, p. 10). Porém, experimentar a continuidade dos processos de escuta e criação disponibilizados pela atividade musical nas Rodas Poéticas pode colocar a docência da educação infantil diante do desafio de constituir-se protagonista na produção linguageira de mundos e de outros sentidos que crianças e adultos-pesquisadores podem aprender na convivência.

Foi assim que inauguramos o projeto "Rodas de Coco" na turma investigada. A experiência de viver os jogos de improvisação e o exercício de abertura de ouvidos provocados pelas ações das crianças na exploração do "paneleiro" contribuíram para sustentar o planejamento, a organização e a realização do encontro propositivo entre 
crianças e adultos a partir da imprevisibilidade dos "ritmos infantis" (CABANELLAS; ESLAVA; ESLAVA; POLÔNIO, 2007). Isto porque

[...] as manifestações linguageiras das crianças e dos artistas convidam a reorganizar o mundo e experimentá-lo, em outras versões, mediados pelos corpos que se mexem, que nem sempre falam com palavras e letras, mas que tanto dizem, provocando a conhecer o desconhecido ao mesmo tempo em que se constroem outros lugares de experiências, estranhando e conhecendo a todo instante. (GOBBI, 2010, p. 2).

As últimas conquistas na legislação ocorreram como fruto de uma história de lutas e reivindicações de diferentes grupos da sociedade civil organizada e significaram um avanço para a educação da infância. Conquistamos os Campos de Experiência, determinamos direitos de aprendizagem e reforçamos as interações e brincadeiras como procedimentos de toda a ação pedagógica. No entanto, novas tensões são evidentes nesse cenário para que as práticas pedagógicas não se apoiem em um modelo de conhecimento pautado na forma escolar, na qual as "aulas" de música possam aparecer para cumprir o ritual do calendário escolar ou oferecer recreação musical (NUNES; CORSINO; DIDONET, 2011, p. 44). Planejar, organizar e realizar Rodas Poéticas têm nos permitido refletir sobre os desafios da organização dos sistemas de ensino em termos da formação docente continuada, de propostas curriculares, de espaços físicos oferecidos e políticas de gestão pública na e para a infância, na especificidade da educação musical.

Portanto, as Rodas Poéticas compreendem, com Malaguzzi (1999, p. 61), que "as coisas relativas às crianças e para as crianças somente são aprendidas através das próprias crianças". Afinal, "as crianças possuem cem linguagens que necessitam de uma escuta atenta, cuidadosa e respeitada por parte do adulto-professor" (RINALDI, 2012, p. 44). Aprender e saber narrá-las é uma forma de produzir conhecimento tão importante quanto escutá-las cotidiana e interrogativamente. Os libretos de criação registram o ato narrativo de brincar com sons das crianças e dos adultos-pesquisadores, movimentando as biografias profissionais e pessoais dos docentes, suas perspectivas, impressões e expectativas. Ao tatuar essa inscrição também podemos nos tornar capazes de interrogar o currículo e propor outras formas de educar musicalmente.

\section{Referências}

AGAMBEN, Giorgio. Infância e História: ensayo sobre la destrucción de la Experiência. Buenos Aires: Adriana Hidalgo Editora, 2011.

AKOSCHKY, Judith et al. La musica em la escuela infantil (0-6). 2. ed. Barcelona: Editora GRAÓ, 2009.

APPEL, Geneviève; DAVID, Myriam. Lóczy, una insolita atencion personal. Barcelona: Octaedro, 2010. 
ATTALI, Jacques. Bruits: essai sur l'économie politique de la musique. Paris: Presses Universitaires de France, 1977.

BACHELARD, Gaston. A poética do espaço. São Paulo: Martins Fontes, 1989.

BARBOSA, Maria Carmen; FOCHI, Paulo Sérgio. Os bebês no berçário: ideias-chave. In: FLORES, Maria Luiza; ALBUQUERQUE, Simone Santos (Orgs.). Implementação do Proinfância no Rio Grande do Sul: perspectivas políticas e pedagógicas. Dados Eletrônicos. Porto Alegre: EDIPUCRS, 2015. p. 57-68.

BARBOSA, Maria Carmen; RICHTER, Sandra Regina Simonis. Campos de Experiência: uma possibilidade para interrogar o currículo. In: FINCO, Daniela; BARBOSA, Maria Carmen; FARIA, Ana Lúcia Goulart. Campos de experiências na escola da infância: contribuições para inventar um currículo de educação infantil brasileiro. Campinas, SP: Edições Leitura Crítica, 2015. p. 185-198.

BELLOCHIO, Claudia Ribeiro (Org.). Educação Musical e Unidocência: pesquisas, narrativas e modos de ser professor de referência. Porto Alegre: Sulina, 2017.

BERLE, Simone. Infância e linguagem: educar os começos. Dissertação (Mestrado em Educação) - Programa de Pós-Graduação em Educação, Universidade de Santa Cruz do Sul, 2013.

BERTOLA, Regina et al. Pra Nhá Terra. Ponto de Partida \& Meninos de Araçuaí. Biscoito Fino (DVD), 2011.

BEYER, Esther. Musikalische und sprachliche Entwicklung in der fruhen Kindheit. Hamburg: Framer, 1994.

BONDIOLI, Anna (Org.). O tempo no cotidiano infantil: perspectivas de pesquisa e estudo de casos. São Paulo: Cortez, 2004.

BORGHI, Battista; GUERRA, Luigi. Manuale di didattica per l'asilo nido. Roma: Laterza, 1999.

BOURSCHEID, Clarice Campos. Escuta estética/poética na creche: encontros musicais com bebês e crianças pequenas. 2014. 228 f. Dissertação (Mestrado em Educação) UNISC, Santa Cruz do Sul, 2014.

BRASIL. Ministério da Educação. Ministério da Educação. Conselho Nacional de Educação. Resolução CEB n. 05, 17 dez. 2009. Institui as Diretrizes Curriculares Nacionais para a Educação Infantil. Diário Oficial República Federativa do Brasil, Brasília, DF, 18 dez. 
2009. Seção 1, p. 18.

. Ministério da Educação. Secretaria da Educação Básica. Base Nacional Comum Curricular. Brasília, 2017. Disponível em: <http://basenacionalcomum. mec.gov.br/>. Acesso em: 5 set. 2017.

BRITO, Teca Alencar. Koellreutter educador: o humano como objetivo da educação musical. São Paulo: Editora da Fundação Peirópolis, 2001.

A música na Educação Infantil: propostas para a formação integral da criança. São Paulo: Peirópolis, 2003.

Quantas músicas tem a Música? Ou algo estranho no museu! São Paulo: Peirópolis, 2009.

CABANELLAS, Isabel; ESLAVA, Juan; ESLAVA, Clara; POLÔNIO, Raquel. Ritmos Infantiles: tejidos de um paisaje interior. Temas de Infancia, 22. Barcelona: Editorial Octaedro, 2007.

CABANELLAS, Isabel; HOYUELOS, Alfredo. Momentos: cantos entre balbuceos. Navarra: Universidad Pública de Navarra, 1998.

DAHLBERG, Gunilla; MOSS, Peter; PENCE, Alan. Qualidade na educação da primeira infância: perspectivas pós-modernas. Porto Alegre: Artmed, 2003.

DAVIDSON, Lyle; SCRIPP, Larry. Educación y desarollo musicales desde um punto de vista cognitivo. In: HARGREAVES, D. J. Infancia y educación artística. Madrid: Morata, 1991. p. 80-111.

EDWARDS, Carolyn; GANDINI, Lella; FORMAN, George. As cem linguagens da criança. Porto Alegre: Artes Médicas, 1999.

FOCHI, Paulo Sergio. Mas os bebês fazem o que no berçário, heim? Documentação ações de comunicação, autonomia e saber-fazer de crianças de 6 a 14 meses em contextos de vida coletiva. 171 f. 2013. Dissertação (Mestrado em Educação) - Universidade Federal do Rio Grande do Sul, Porto Alegre, 2013.

FONTERRADA, Marisa. O lobo no labirinto: uma incursão à obra de Murray Schafer. São Paulo: Editora da UNESP, 2004.

De tramas e fios: um ensaio sobre música e educação. São Paulo: Editora UNESP; Rio de Janeiro, FUNARTE, 2008. 
2015.

FREIRE, Madalena. A paixão de conhecer o mundo. Rio de Janeiro: Paz e Terra, 1983.

Observação, registro e reflexão: Instrumentos metodológicos I. São Paulo: Espaço Pedagógico, 1996.

GOBBI, Márcia. Múltiplas linguagens de meninos e meninas no cotidiano da Educação Infantil, 2010. Consulta Pública sobre Orientações Curriculares Nacionais na Educação Infantil. Disponível em: <http://portal.mec.gov.br/index.php?/temid=1096\&i$\mathrm{d}=15860$ \&option=com_content\&view=article>. Acesso em: 01 abr. 2016.

GORDON, E. Teoria da aprendizagem musical para recém-nascidos e crianças em idade pré-escolar. Lisboa: Fundação Calouste Gulbenkian, 2000.

HEYWOOD, Colin. Uma história da infância: da Idade Média á época contemporânea no Ocidente. Porto Alegre: Artmed, 2004.

HOYUELOS, Alfredo. La ética em el pensamento y obra pedagógica de Loris Malaguzzi. Barcelona: Octaedro, 2004.

Prólogo. In: CABANELLAS, Isabel; ESLAVA, Juan; ESLAVA, Clara; POLÔNIO, Raquel. Ritmos Infantiles: tejidos de um paisaje interior. Temas de Infancia, 22. Editorial Octaedro: Barcelona, 2007.

ILARI, Beatriz; BROOK, Angelita (Orgs.). Música e educação infantil. Campinas, SP: Papirus, 2013.

ILARI, Beatriz; YOUNG, Susan (Orgs.). Children's home musical experiencies across the world. Bloomington: Indiana University Press, 2016.

KAERCHER, Gládis Elise Pereira da Silva. As linguagens, a formação do leitor e a ação pedagógica na Educação Infantil: apontamentos. In: FLORES, Maria Luiza Rodrigues; ALBUQUERQUE, Simone. Implementação do Proinfância no Rio Grande do Sul: perspectivas políticas e pedagógicas . Porto Alegre: EDIPUCRS, 2015. p. 322.

KATER, Carlos; LOBÃO, Paulo. Musicalização através da Canção Popular Brasileira. Cadernos de Estudo. São Paulo: Atravéz e Escola de Música da UFMG, 2001.

Musicantes e o boi brasileiro: uma história com [a] música. São Paulo: Musa, 2013. 
A Música da Gente. CEU, São Bernardo, SP: Scania; Secretaria Municipal de Educação de São Bernardo, 2016.

LARROSA, Jorge. Notas sobre a experiência e o saber de experiência. Tradução João Wanderley Geraldi. Revista Brasileira de Educação, Rio de Janeiro, n. 19, p. 20-28, jan./ fev./mar./abr. 2002.

LE BRETON, David. As paixões ordinárias: antropologia das emoções. Petrópolis: Vozes, 2009.

LINO, Dulcimarta Lemos. Barulhar: a escuta sensível da música nas culturas da infância. 395 f. 2008. Tese (Doutorado em Educação) - Faculdade de Educação, Universidade Federal do Rio Grande do Sul, Porto Alegre, 2008.

. Corpos no som: ensaios de escuta. In: CAMARGO, leda (Org.). Escola hoje [recurso eletrônico] quem te define? Santa Cruz do Sul: EDUNISC, 2014. p. 63-75. Disponível em: <http://www.unisc.br/edunisc>. Acesso em: 23 jun. 2014.

Abracadabra: o encontro de bebês e crianças pequenas com música. Revista Eventos Pedagógicos - Educação de 0 a 3 anos em espaços de vida coletiva, v. 6, n. 3, 16. ed., edição especial temática, p. 116-131, ago./out. 2015.

Diário de Campo. Pesquisa: Educação Musical no Curso de Pedagogia da UFRGS. Projeto de Pesquisa, FACED-UFRGS, 2017.

MALAGUZZI, Loris. Histórias ideias e filosofia básica. In: EDWARDS, Carolyn; GANDINI, Lella; FORMAN, George. As cem linguagens da criança. Porto Alegre: Artes Médica, 1999.

2001.

La educación infantil em Reggio Emilia. Barcelona: Octaedro; Rosa Sensat,

MERLEAU-PONTY, Maurice. A linguagem indireta e as vozes do silêncio. In: Signos. São Paulo: Martins Fontes, 1991.

Fenomenologia da percepção. São Paulo: Martins Fontes, 1999a.

O visível e o invisível. São Paulo: Editora Perspectiva, 1999b.

A prosa do mundo. São Paulo: Cosac Naify, 2012.

NUNES, Maria Fernanda Rezende; CORSINO, Patricia; DIDONET, Vital. Educação Infantil no Brasil: primeira etapa da educação básica. Brasília: UNESCO, Ministério da Educação/ 
Secretaria de Educação Básica, Fundação Orsa, 2011. p. 102.

OSTETTO, Luciana Esmeralda. Encontros e encantamentos na educação infantil. Campinas, SP: Papirus, 2000.

OSTETTO, Luciana. A arte no itinerário da formação de professores: acender coisas por dentro. Reflexão e Ação, Santa Cruz do Sul, v. 14, n. 1, p. 29-43, jan./jun. 2006.

Educação Infantil: saberes e fazeres da formação de professores. Campinas, SP: Papirus, 2008.

OSTETTO, Luciana (Org.). Educação Infantil: saberes e fazeres da formação de professores. Campinas,SP: Papirus, 2015 [2012].

PEREIRA, Maria Amélia. Casa Redonda: Centro de Estudos. São Paulo: Livre, 2013.

RICHTER, Sandra R S; FRONCKOWIAK, A. C. Experiência poética e aprendizagem na infância. 93 f. Relatório Técnico Processo N. 477709/2007-09 CNPq. 2010.

A tensão lúdica entre brincar e aprender na infância. Pátio Educação Infantil, ano IX, n. 27, p. 39-41, 2011.

RICHTER, Sandra R. S.; BOURSCHEID, Clarice. Encontros estéticos/poéticos entre música e bebês na creche. Reflexão\&Ação, Santa Cruz do Sul, v. 22, n. 1, p. 32-58, jan./jun. 2014.

RICHTER, Sandra R. S.; BERLE, Simone. A pedagogia como gesto poético. Educação \& Realidade, Porto Alegre, v. 40, n. 4, p. 1027-1043, out./dez. 2015.

RICHTER, Sandra R. S.; FRONCKOWIAK, A. C.; LINO, Dulcimarta L. Dimensão poética das linguagens e educação da infância. 82 f. Relatório Técnico. UNISC/ ProPPG, PPGEdu, 2013.

RICOEUR, Paul. Interpretação e ideologias. Rio de Janeiro: Livraria Francisco Alves, 1988.

RINALDI, Carla. Diálogos com Reggio Emilia: escutar, investigar, aprender. São Paulo: Paz e Terra, 2012.

ROCHA, Eloisa Acires Candal. A pedagogia e a educação infantil. Revista Brasileira de Educação, n. 16, p. 27-34, jan./mar. 2001.

SARMENTO, Manuel Jacinto. Imaginário e culturas da infância. Cadernos de Educação FaE/UFPel, Pelotas, p. 51 jul/.dez. 2003. 
SERAFINE, Mary L. Music as cognition. New York: Columbia University Press, 1988.

SILVA, Lucilene. Eu vi as três meninas: música tradicional da infância na Aldeia de Carapicuíba. Carapicuíba, SP: Zerinho ou Um, 2014.

SLOBODA, J. (Org.). Generative processes in music. Oxford: Clarendon, 1988.

SLOBODA, J; DELIEGE, Irene. Origins and development of musical competence. New York: Oxford University, 1996.

SOARES, Magda B. Didática, uma disciplina em busca de sua identidade. Ande, São Paulo, v. 5, n. 9, p. 39-42, 1985.

SOTO, Claudia; VIOLANTE, Rosa. Experiencias estéticas en los primeiros anos: reflexiones y propuestas de enseñanza. Ciudad Autónoma de Buenos Aires: Paidós, 2016.

TOMASELLI, Anna; ZOCHI, Alessandra. Perché documentare. In: FIRENZE. Linea guida: per i servisi educativi ala prima infanza - Documentazione. Azzano São Paolo: Edizioni Junior, 2009.

WAUSCHAUER, Cecilia. A roda e o registro: uma parceria entre o professor, alunos e o conhecimento. Rio de Janeiro: Paz e Terra, 1993. 